Supplementary Information for

\title{
Ionic Liquid Enriches the Antibiotic Resistome, Especially Efflux Pump Genes, Before Significantly Affecting Microbial Community Structure
}

Xiaolong Wang, ${ }^{\dagger}$ Zeyou Chen, ${ }^{\dagger}$ Quanhua $\mathrm{Mu},{ }^{\dagger}$ Xinyan $\mathrm{Wu},{ }^{\dagger}$ Jingjing Zhang, ${ }^{\dagger}$ Daqing Mao, ${ }^{\dagger} \mathrm{Yi}$

Luo, ${ }^{*} \dagger$ and Pedro J.J. Alvarez* ${ }^{*}$

$\dagger$ College of Environmental Science and Engineering, Ministry of Education Key Laboratory of

Pollution Processes and Environmental Criteria, Nankai University, Tianjin 300071, China

$\$$ School of Medicine, Nankai University, Tianjin 300071, China

${ }^{\S}$ Dept of Civil and Environmental Engineering, Rice University, Houston, Texas 77005, USA

(Xiaolong Wang, Zeyou Chen, and Quanhua Mu contributed equally to this work.)

*Corresponding Authors Phone: +86 (22) 85358553, E-mail: luoy@nankai.edu.cn

*Corresponding Authors Phone: (713) 348-5903, alvarez@rice.ed 


\section{Influence of [BMIm] [PF6] exposure on plasmid replication}

2 To identify the influence of [BMIm][PF6] exposure on plasmid replication, E.coli DH5 $\alpha$ carrying

3 a conjugative plasmid (RP4) and E.coli DH5 $\alpha$ carrying a non-conjugative plasmid (pBR322) were

4 selected to compare changes in plasmid copy number after exposure to [BMIm][PF6]. The E. coli

5 DH5 $\alpha$ cells harboring RP4 or pBR322 were cultured in LB medium at $37^{\circ} \mathrm{C}$ with addition of 100

$6 \mu \mathrm{g} / \mathrm{ml}$ of ampicillin for overnight separately in culture tubes. Then, the bacteria was washed with

7 the PBS buffer for three times, resuspended with the PBS buffer. The bacterial density was

8 adjusted to the $1 \mathrm{E} 7 \mathrm{CFU} / \mathrm{ml}$ with the PBS buffer, spiked with [BMIm][PF6] at the final

9 concentrations of $0.1 \mathrm{~g} / \mathrm{L}$ and $1.0 \mathrm{~g} / \mathrm{L}$, and one [BMIm] [PF6]-free control. Each group contains

10 four biological replicates. All the groups were incubated stationary, which condition is same with

11 that of the freshwater microcosms. After $16 \mathrm{~h}$ exposure, total DNA was extracted from each of the

12 biological replicates, the extraction was performed using the bacterial DNA Isolation Kit

13 (OMEGA BioTek D3350-01), following a method for bacterial cells described in the

14 manufacturer's instructions. The DNA extracted from E. coli carrying the plasmid was normalized

15 to $2 \mathrm{ng} / \mu \mathrm{l}$ with deionized and distilled water for consistent QPCR assay. The detection of the

16 plasmid and the host chromosomal DNA was achieved using two separate primer sets, specific for

17 the plasmid $\beta$-lactamase gene (bla $a_{\mathrm{TEM}-1}$ of the plasmid RP4 and pBR322) and for the chromosomal

18 d-1-deoxyxylulose 5-phosphate synthase gene (dxs of the E.coli), respectively. Since both bla $a_{\mathrm{TEM}-1}$

19 and dxs are single-copy genes in selected plasmids (RP4 and pBR322) and E. coli chromosomal

20 DNA, respectively, the plasmid copy number can be determined as the copy ratio of bla $a_{\mathrm{TEM}-1}$ to

21 dxs. The primers (Table S4), plasmids, bacteria (Table S2), and detail procedure of detection 
22 plasmid copy number was shown as the Supporting Information. The plasmid copy number was

23 determined by real-time qPCR shown as the previous study. ${ }^{1}$

\section{Quantification of the target genes}

The presence of the antibiotic resistance genes (ARGs) was determined by qualitative PCR assays on a Biometra T100 gradient (Biometra, Germany). PCR assays for ARGs and 16S rRNA gene were conducted in a $25-\mu \mathrm{L}$ volume reaction system containing $0.5 \mu \mathrm{L}$ diluted DNA extract as the template, $0.2 \mu \mathrm{M}$ of each primer, $0.2 \mathrm{mM}$ dNTPs, 1.25 U EasyTaq DNA Polymerase (TransGen, China), and 12.5 $\mu \mathrm{L}$ 10x EasyTaq Buffer (TransGen, China). DNA extracts were diluted from 10 to 50-fold, and 16S rRNA gene PCR was performed to optimize the template concentration. For each DNA extract, duplicate PCR tubes were analyzed for the detection of the target genes. A negative control consisting of the reaction mixture without DNA was used in each PCR run. The PCR reaction procedure involved initial denaturation at $95{ }^{\circ} \mathrm{C}$ for $5 \mathrm{~min}$ followed by 35 cycles of $95^{\circ} \mathrm{C}$ for $30 \mathrm{sec}$ (denaturing), $30 \mathrm{sec}$ of annealing at different annealing temperatures, and $72{ }^{\circ} \mathrm{C}$ for $30 \mathrm{sec}$ (extension), with a final extension step for $7 \mathrm{~min}$ at $72{ }^{\circ} \mathrm{C}$. PCR products were analyzed by electrophoresis on a $1.0 \%$ agarose gel in $1 \times$ TAE buffer and then cloned into Escherichia coli DH5 $\alpha$ using the pEASY-T3 Cloning Kit (Transgene Beijing, China); sequencing validation was then performed (Beijing Genomics Institute, Beijing, China). The absolute abudance of ARGs in sediment was shown as Table S5.

\section{Enrichment of Functional Genes Confirming HGT}

The metagenomic data were also blasted against NCBI-nr database and assigned to the SEED 
42 database to discern changes in the abundance of functional genes after [BMIm][PF6] exposure.

43 Functional genes related to respiration and energy production (i.e., "Respiration", "RNA

44 metabolism", "Nucleic Acids", and "Protein Metabolism") were significantly enriched $(p<0.05$,

45 Fisher's exact test, Figure S6) in the [BMIm][PF6]-exposed metagenomes, indicating higher

46 metabolism and energy production capacity after the [BMIm][PF6] exposure. Previous studies

47 reported that genes involved in energy conversion as well as the transport and metabolism of

48 inorganic ions and amino acids are vital for HGT-related genes. ${ }^{2}$ The "Cell Wall and Capsule"

49 subsystem including both "Gram-positive cell wall components" and "Gram-negative cell wall

50 components" subsystems were also enriched in [BMIm][PF6]-exposed groups regardless of

51 concentrations (Figure S6).

52 Further analysis of the "Virulence, Disease and Defense" subsystem showed more reads

53 assigned to Resistance to antibiotics and toxic compounds in the [BMIm][PF6]-exposed

54 metagenomes (Figure S7), which is consistent with the result obtained for BLASTX against the

55 SARG database. Moreover, in the "Membrane Transport" subsystem, functional genes related to

56 "Protein and nucleoprotein secretion system (Figure S8), Type IV" were enriched in the

$57 \quad[\mathrm{BMIm}][\mathrm{PF} 6]$-exposed groups $(p<0.05$, Fisher's exact test). Type IV secretion system (T4SS) is

58 responsible for translocation of proteins or protein-DNA complexes, and some of them are directed

59 related to bacterial conjugation..$^{3-5}$

60 Enrichment of functional genes related to bacterial conjugation in the [BMIm][PF6]-exposed

61 groups supports the notion that HGT was promoted by [BMIm][PF6]. Conjugation was likely the 
62 primary mechanism for ARG dissemination. This process is under the regulation of the mating

63 pair formation system gene $\operatorname{tr} b \mathrm{Bp}$ as well as plasmid transfer and replication system gene $\operatorname{trfAp} .^{6}$

64 In our previous study, we showed that [BMIm] [PF6] treatment promotes expression of these two

65 genes, as well as that of conjugative genes $\operatorname{tra\mathrm {F}}, k i l \mathrm{~A}$ and kilB to enhance conjugative transfer of

66 plasmid RP4 between E. coli cells and E. coli-Salmonella enterica. ${ }^{7}$ However, the tra-like, trb-like

67 or kil-like functional genes, normally located in the conjugative plasmid, were not enriched in the

68 present study, which is likely due to the difficulty in plasmid assembly of short reads length

69 generated by Illumina sequencing so that we can retrieve only a limited fraction of plasmid

70 sequence. Nonetheless, several other HGT related genes were enriched in the [BMIm][PF6]-

71 exposed freshwater microbial communities. Altogether, these results indicated that bacteria in the

72 [BMIm][PF6]-exposed microcosms became functionally better prepared for HGT of ARGs. 


\begin{tabular}{ll}
\hline Analyte & Concentration \\
\hline Enrofloxacin (ng/L) & 36.0 \\
Tetracycline (ng/L) & 300.4 \\
Sulfamethazine (ng/L) & 0.4 \\
Ciprofloxacin (ng/L) & 26.8 \\
Ofloxacin (ng/L) & 10.0 \\
Oxytetracycline (ng/L) & 11.6 \\
Sulfamethoxazole (ng/L) & 82.4 \\
Doxycycline (ng/L) & 5.2 \\
Streptomycin (ng/L) & 50.5 \\
Chlortetracycline (ng/L) & 16.8 \\
Roxithromycin (ng/L) & 7.2 \\
Zinc (ug/L) & 50.0 \\
Copper (ug/L) & 10.0 \\
TOC (mg/L) & 16.8 \\
NH $-\mathrm{N}(\mathrm{mg} / \mathrm{L})$ & 3.2 \\
Dissolved P (mg/L) & 0.2 \\
pH & 7.2 \\
Water temperature $\left({ }^{\circ} \mathrm{C}\right)$ & 28.0 \\
\hline
\end{tabular}

76

Table S2 Strains and plasmids used in this study

\begin{tabular}{cc}
\hline Strains or plasmid & Description \\
\hline E. coli $\mathrm{K} 12:$ Td-Tomato & Host of plasmid RK2::EGFP, $\mathrm{Km}^{\mathrm{R}}$, tagged with \\
RK2::EGFP & Td-Tomato in chromosome \\
RP4 & Conjugative plasmid, Ap ${ }^{\mathrm{R}}$, tagged with EGFP \\
pBR322 & Conjugative plasmid, $\mathrm{Km}^{\mathrm{R}}, \mathrm{Amp}^{\mathrm{R}}, \mathrm{Tc}^{\mathrm{R}}$ \\
E.coli $\mathrm{DH} 5 \alpha$ & Non-conjugative plasmid, $\mathrm{Amp}^{\mathrm{R}}, \mathrm{Tc}^{\mathrm{R}}$ \\
\hline
\end{tabular}

*,Km: Kanamycin, Amp: Ampcillin, Tc: Tetrycycline, Ap, Apramycin

81

82 


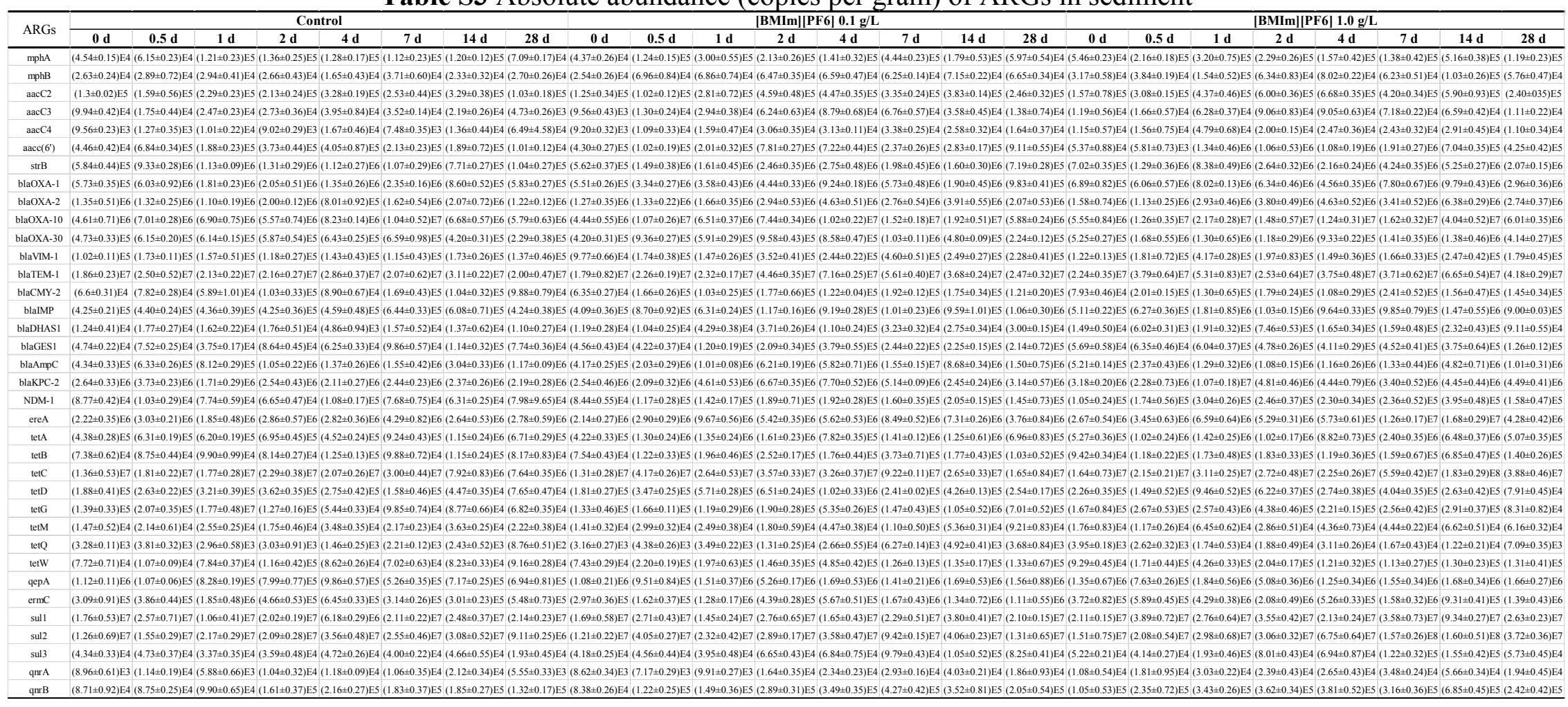


Table S4 Primers used in the plasmid copy number detection

\begin{tabular}{ccccc}
\hline \multirow{2}{*}{ Target } & Primers $\left(\mathbf{5}^{\prime} \rightarrow \mathbf{3}^{\prime}\right)$ & Length $(\mathbf{n t})$ & $\begin{array}{c}\text { Primer } \\
\text { position }\end{array}$ & $\begin{array}{c}\text { Product } \\
\text { size (bp) }\end{array}$ \\
\hline \multirow{2}{*}{ la $_{\mathrm{TEM}-1}$} & F: CTACGATACGGGAGGGCTTA & 20 & $3382-3401$ & \\
& R: ATAAATCTGGAGCCGGTGAG & 20 & $3443-3462$ & \\
\hline \multirow{2}{*}{$d x s$} & F: CGAGAAACTGGCGATCCTTA & 20 & $1509-1528$ & \multirow{2}{*}{113} \\
& R: CTTCATCAAGCGGTTTCACA & 20 & $1602-1621$ & \\
\hline
\end{tabular}

89

90

91

92

94 Figure S1 Culturable bacteria bacteria concentrations following exposure to $1 \mathrm{~g} / \mathrm{L}$ of $[\mathrm{BMIm}][\mathrm{PF} 6]$ for $16 \mathrm{~h}$ in

95 freshwater microcosms, and resulting susceptibility to various antibiotics (Tetracycline, Ampicillin,

96 Ciprofloxacin, Erythromycin or Streptomycin). Each value is shown as mean $\pm \mathrm{SD}$ of three biological replicates.

97 Significant differences between groups exposed to ionic liquid versus unexposed controls were determined with 98 the Student's $t$ test. $\left({ }^{*}, p<0.05\right)$.

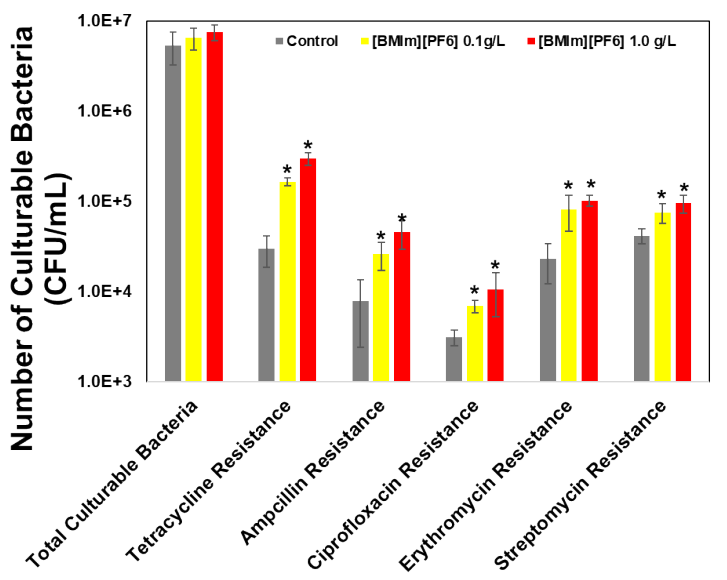

\begin{tabular}{ccccc}
\multicolumn{2}{c}{ Table S5 Influence of [BMIm][PF6] exposure on plasmid copy number } \\
\cline { 2 - 5 } Group & \multicolumn{2}{c}{ RP4 plasmid } & \multicolumn{2}{c}{ pBR322 plasmid } \\
\cline { 2 - 5 } & $0 \mathrm{~h}$ & $3.7 \pm 0.7$ & $0 \mathrm{~h}$ & $16 \mathrm{~h}$ \\
\hline Control & $4.2 \pm 0.5$ & $4.1 \pm 2.7$ & $24.3 \pm 1.9$ \\
$0.1 \mathrm{~g} / \mathrm{L} \mathrm{IL}$ & $3.7 \pm 0.9$ & $4.0 \pm 1.1$ & $20.8 \pm 3.2$ & $22.2 \pm 4.0$ \\
$1.0 \mathrm{~g} / \mathrm{L}$ IL & $4.5 \pm 1.3$ & $4.3 \pm 0.9$ & $23.4 \pm 3.3$ & $21.9 \pm 2.9$ \\
\hline
\end{tabular}

*Biological replicates, $\mathrm{n}=4$ 

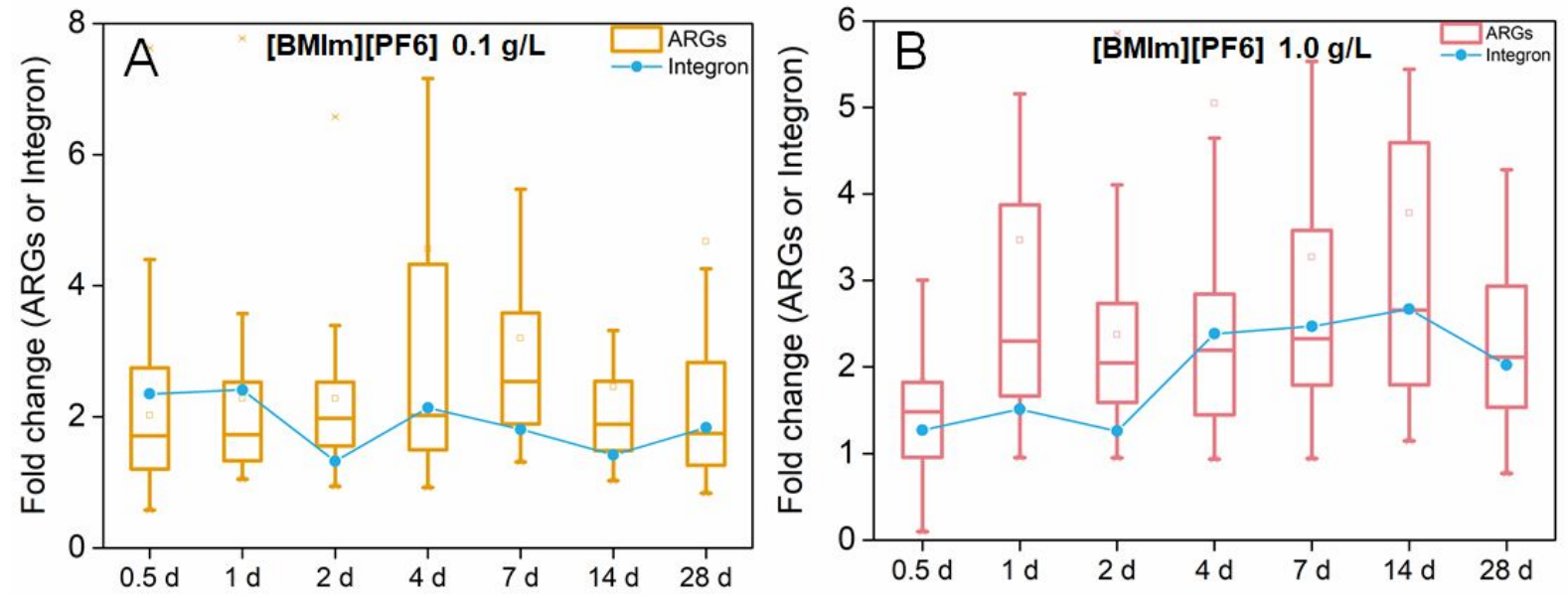

100 Figure S2 The fold change of ARGs and Class 1 integron after exposure to [BMIm][PF6] (0.1 g/L) (A) or (1.0

$101 \mathrm{~g} / \mathrm{L})(\mathbf{B})$ for different durations in sediment microcosm. Insignificant differences among individual period groups

102 were tested with LSD multiple comparison in $0.1 \mathrm{~g} / \mathrm{L}$ group $(\mathbf{A})$ and $1.0 \mathrm{~g} / \mathrm{L}$ group $(\mathbf{B})$, Bonferroni corrected. $p$ $103>0.05$.

104

105

107

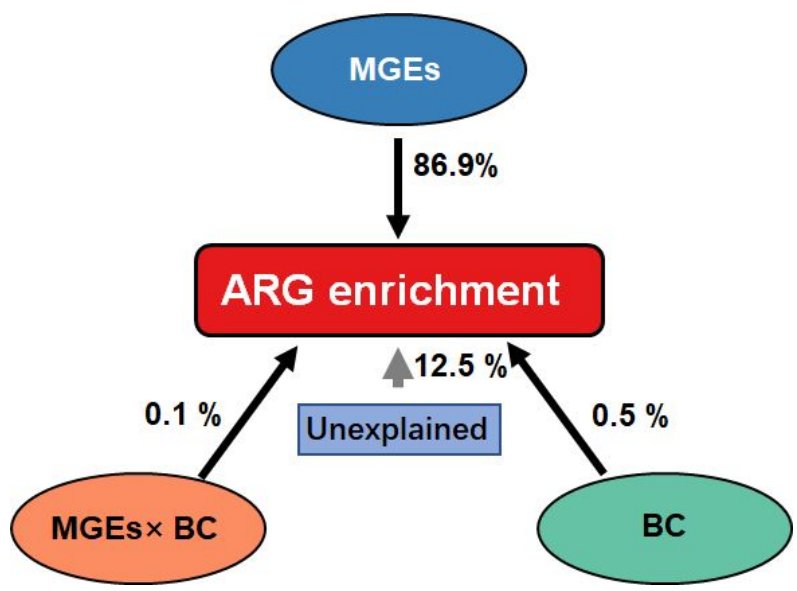

Figure S3 Variantion partitioning analysis (VPA) differentiating contributions of mobile genetic elements (MGEs) and bacterial community (BC) to the ARG enrichment. 


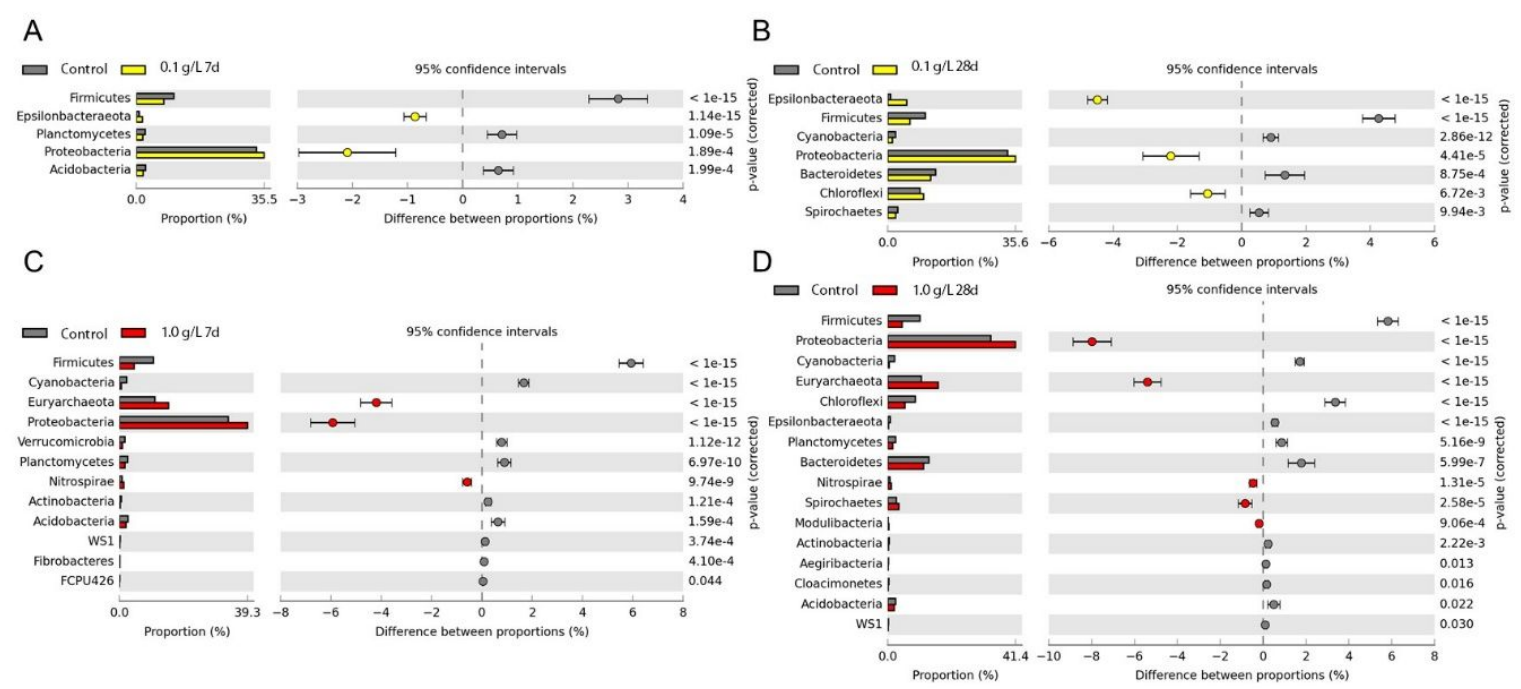

108

109 Figure S4 Shift of microbial community of [BMIm][PF6] exposure at phylum level during different exposure

110 periods in sediment microcosm. $0.1 \mathrm{~g} / \mathrm{L}$ for 7 days (A), 28 days (B) and $1.0 \mathrm{~g} / \mathrm{L}$ for 7 days (C), 28 days (D).

111 Only significant (Fisher's exact test, $p<0.05$ ) changes are shown.

112
113

114 Figure S5 PCoA analysis of the bacterial communities from Control, IL $0.1 \mathrm{~g} / \mathrm{L}$, and IL $1.0 \mathrm{~g} / \mathrm{L}$ during different

\footnotetext{
exposure periods ( 0.5 day, 7 days, and 28 days) in sediment microcosm based upon the weighted UniFrac method.
}

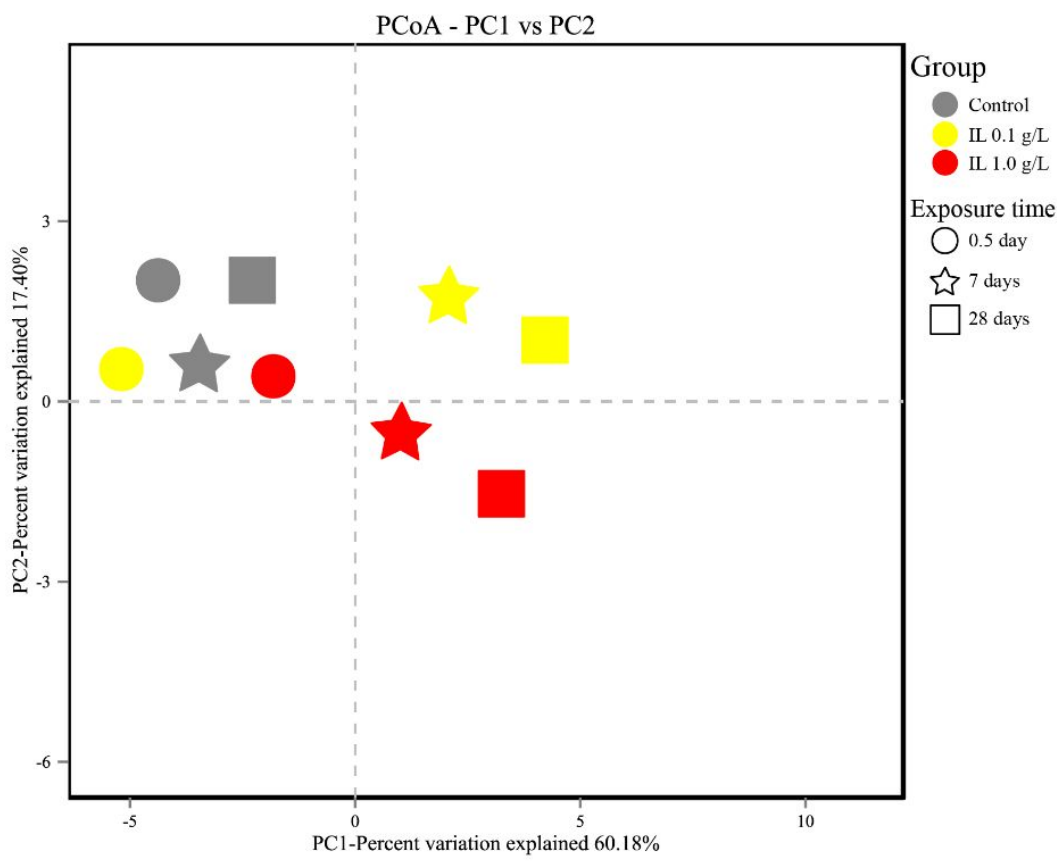




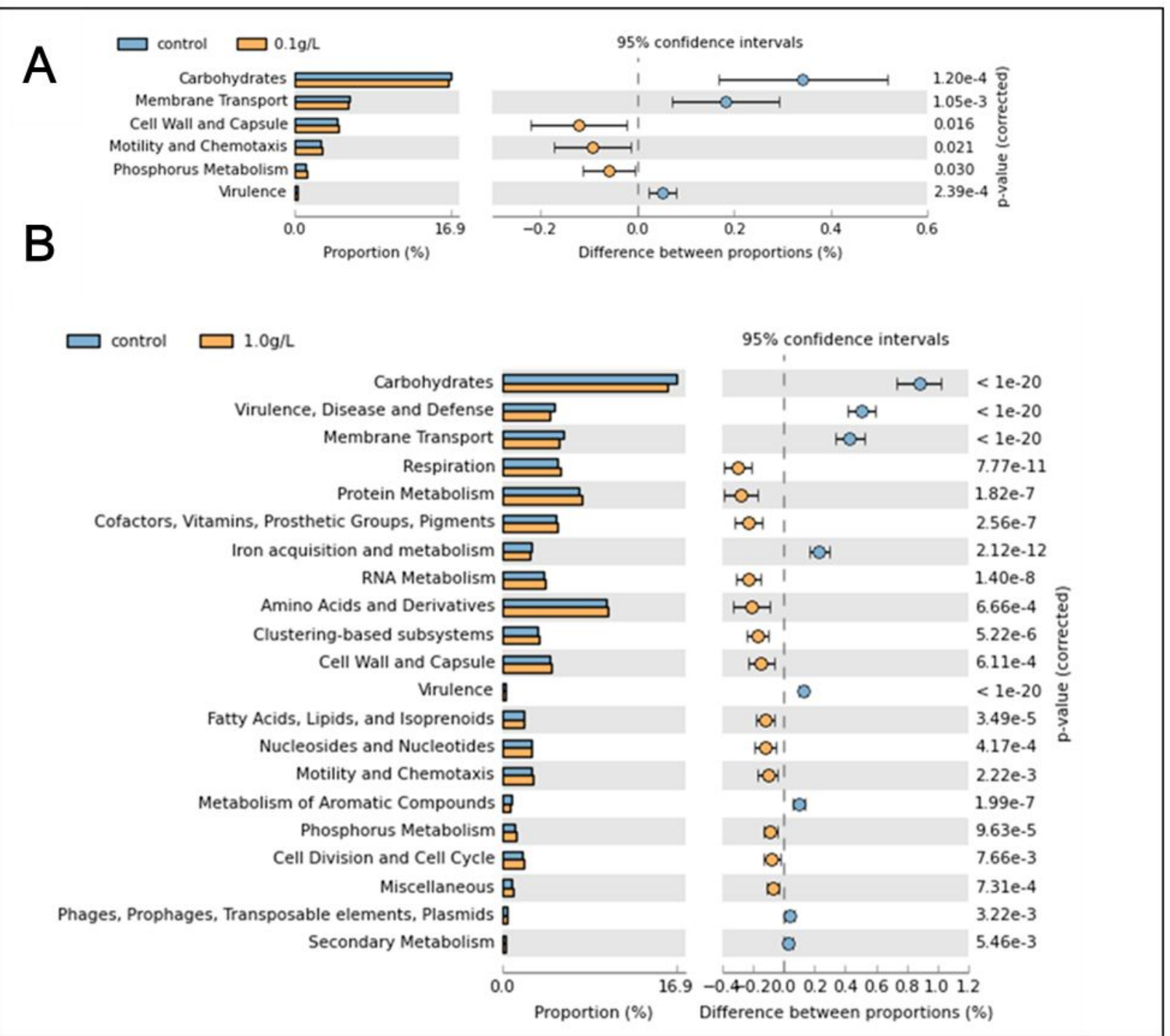

117 Figure S6 Enrichment of functional genes after $0.1 \mathrm{~g} / \mathrm{L}(\mathbf{A})$ or $1.0 \mathrm{~g} / \mathrm{L}(\mathbf{B})[\mathrm{BMIm}][\mathrm{PF} 6]$ treatment as assigned 118 to SEED systems. Only significant (Fisher's exact test, $p<0.05$, Bonferroni corrected) changes are shown. 


\section{A}

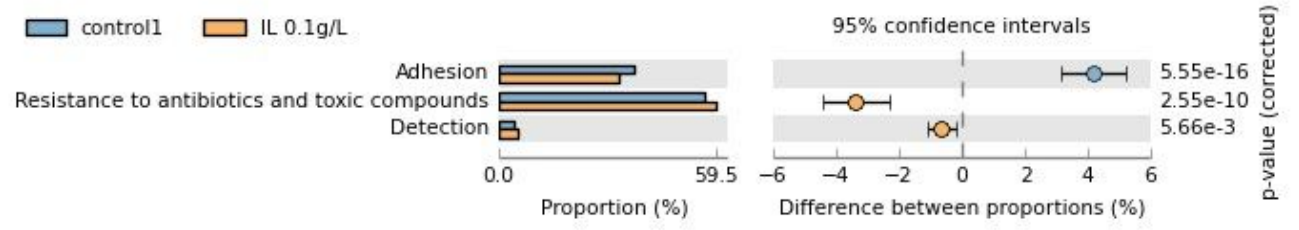

\section{B}

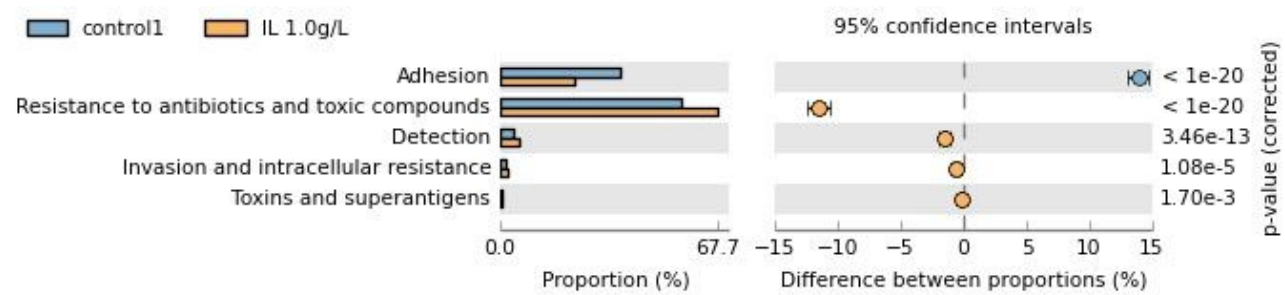

120

121 Figure S7 Changes in functional genes in Virulence, Disease and Defense subsystem after 0.1 g/L (A) and 1.0

$122 \mathrm{~g} / \mathrm{L}(\mathbf{B})[\mathrm{BMIm}][\mathrm{PF} 6]$ exposure. Only significant (Fisher's exact test, $p<0.05$, Bonferroni corrected) changes

123 were shown.

124 
A

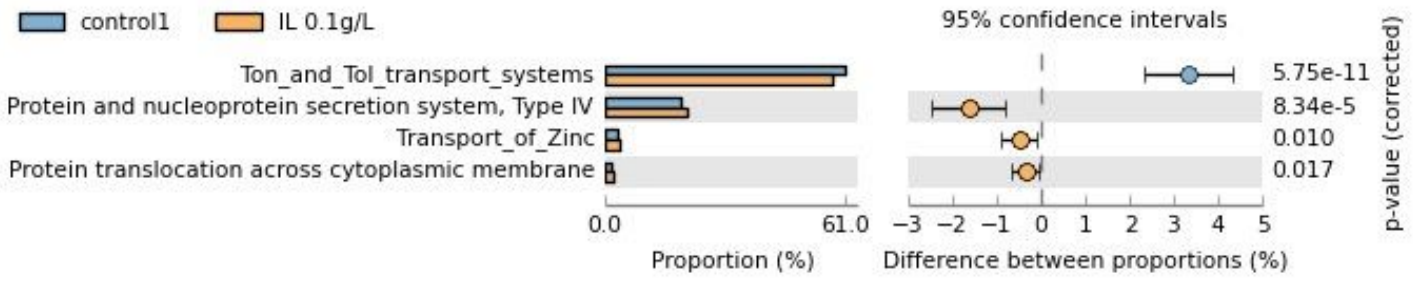

B

$\square$ controll $\square$ IL 1.0g/L

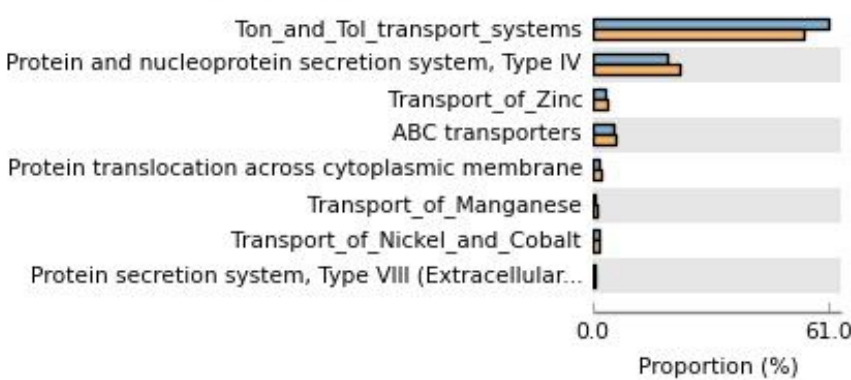

$95 \%$ confidence intervals

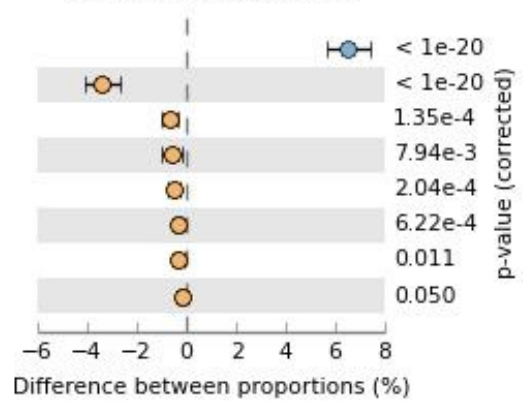

125

126 Figure S8 Changes in functional genes in Membrane Transport subsystem after $0.1 \mathrm{~g} / \mathrm{L}(\mathbf{A})$ and $1.0 \mathrm{~g} / \mathrm{L}(\mathbf{B})$

$127[\mathrm{BMIm}][\mathrm{PF} 6]$ treatment. Only significant (Fisher's exact test, $p<0.05$, Bonferroni corrected) changes were 128 shown.

129 


\section{$130 \quad$ References}

131 1. Lee, C. ; Kim, J. ; Shin, S. G. ; Hwang, S., Absolute and relative QPCR quantification of

132 plasmid copy number in Escherichia coli. J Biotechnol 2006, 123, (3), 273-280.

133 2. Fuchsman, C. A. ; Collins, R. E. ; Rocap, G. ; Brazelton, W. J., Effect of the environment

134 on horizontal gene transfer between bacteria and archaea. PeerJ 2017, 5, e3865.

135 3. Guglielmini, J.; de la Cruz, F.; Rocha, E. P. C., Evolution of conjugation and type IV

136 secretion systems. Molecular biology and evolution 2013, 30, (2), 315-331.

137 4. Wallden, K. ; Rivera-Calzada, A. ; Waksman, G., Type IV secretion systems: versatility and

138 diversity in function. Cell Microbiol 2010, 12, (9), 1203-1212.

139 5. Trokter, M. ; Waksman, G., Translocation through the Conjugative Type IV Secretion System

140 Requires Unfolding of Its Protein Substrate. J Bacteriol 2018, 200, (6), e00615-17.

141 6. Thomas, C. M. ; Nielsen, K. M., Mechanisms of, and barriers to, horizontal gene transfer

142 between bacteria. Nat. Rev. Microbiol. 2005, 3, (9), 711-721.

143 7. Wang, Q. ; Mao, D. ; Luo, Y., Ionic Liquid Facilitates the Conjugative Transfer of

144 Antibiotic Resistance Genes Mediated by Plasmid RP4. Environ. Sci. Technol. 2015, 49, (14), $1458731-8740$.

146 